\title{
A APRENDIZAGEM DO PRESENTE DO SUBJUNTIVO DO ESPANHOL EM ORAÇÕES TEMPORAIS COM CUANDO POR UNIVERSITÁRIOS BRASILEIROS: OS EFEITOS DA INTERVENÇÃO INSTRUCIONAL NA REDUÇÃO DE TRANSFERÊNCIA LINGUÍSTICA
}

\section{THE LEARNING OF SUBJUNCTIVE PRESENT TENSE OF SPANISH IN TEMPORAL SENTENCES WITH CUANDO BY BRAZILIAN COLLEGE STUDENTS: THE EFFECTS OF INSTRUCTIONAL INTERVENTION IN LANGUAGE TRANSFER REDUCTION}

\author{
Gisele Benck de Moraes* \\ Eduardo de Oliveira Dutra** \\ Taíse Simioni $^{* * *}$
}

RESUMO: Neste estudo analisamos e discutimos o papel da intervenção instrucional na redução da não aplicação do presente do subjuntivo do espanhol, em orações subordinadas temporais com cuando, por universitários brasileiros. Tarefas de produção oral e escrita foram utilizadas para a obtenção de dados, os quais foram submetidos ao Teste Normal Padrão. Fizeram parte deste estudo 12 participantes de uma universidade privada. Os resultados, de modo geral, sugeriram, em curto prazo, a redução das formas alternativas. Tal redução se manteve estável em médio prazo, ou seja, houve maior aplicação de estruturas alternativas no pré-teste e diminuição de sua aplicação nas fases pós-instrucionais. Logo, partindo de uma relação inversamente proporcional, o tratamento pedagógico surtiu efeito durável sobre a aprendizagem do presente do subjuntivo, em orações temporais com cuando. Acrescentamos a isso o fato de que a redução da transferência linguística e de outros casos de formas alternativas pode ser útil também como evidência favorável dos benefícios instrucionais. Palavras-chave: presente do subjuntivo; instrução com foco na forma; espanhol.

ABSTRACT: In this study, we analyze and discuss the role of the instructional intervention in the reduction of the non-application of the subjunctive present tense of Spanish in temporal

\footnotetext{
* Universidade de Passo Fundo, Passo Fundo, RS. Brasil. gbenck@upf.br ** Universidade Federal do Pampa, Bagé, RS. Brasil. eduale@terra.com.br *** Universidade Federal do Pampa, Bagé, RS. Brasil. taise.simioni@unipampa.edu.br
} 
sentences with cuando by Brazilian college students. Tasks as oral and written production were used to obtain data, which were submitted to Standard Normal Test. Twelve students from a private university participated in this study. In a short term, the results suggested the reduction of the alternative forms. These reductions have kept stable in medium term, that is, there was a greater application of cases of language transfer in the pre-test and a reduction of its application in the post-instructional phases. Thus, starting from an inversely proportional relation, the pedagogical treatment had provided a durable effect on the learning of the subjunctive present tense in temporal sentences with cuando. We add to this the fact that the reduction of language transfer also can be useful as favorable evidence of the instructional benefits.

Keywords: subjunctive present tense; form-focused instruction; Spanish.

\section{INTRODUÇÃO}

$\mathrm{Na}$ área de aquisição de segunda língua ${ }^{1}$ (doravante, ASL), existem estudos (BOÉSSIO, 2003; COSTA, 2004; MORAES, 2014; DUTRA, 2015), no âmbito da aprendizagem do espanhol como língua estrangeira (doravante, LE), cujos resultados apontaram dificuldades do brasileiro no que tange à aprendizagem de formas linguísticas pertencentes a distintos níveis da língua-alvo. Como professores de ensino superior, observamos que os alunos, por exemplo, não empregam adequadamente a forma verbal presente do subjuntivo com a conjunção subordinada adverbial cuando, como no caso de Cuando viajes, comprarás muchos regalos, uma vez que existe uma tendência de emprego do que corresponde, em português brasileiro (doravante, PB), ao futuro do subjuntivo na oração subordinada, como em Cuando viajares, comprarás muchos regalos.

No âmbito da instrução com foco na forma (doravante, IFF), no contexto do País, há evidências dos benefícios das intervenções pedagógicas adotadas no que tange ao ensino de formas linguísticas na sala de aula de LE. Contudo, cabe destacarmos que há menos registro de investigações (LOOSE, 2006; DUTRA, 2015) que trataram dos benefícios do tratamento instrucional, em curto e em médio ou longo prazos, com base em índices de aplicação das formas metas e simultaneamente na sua não produtividade ${ }^{2}$, do que pesquisas a respeito da IFF que trataram dos efeitos da durabilidade da intervenção pedagógica, baseadas, primordialmente, na análise e discussão de dados provenientes de aplicação da(s) forma(s)-alvo.

Concordamos com a afirmação de que a redução da transferência linguística pode ser um fator de reforço das evidências favoráveis no que tange aos benefícios

1. Neste estudo segunda língua é sinônimo de língua estrangeira.

2. Sinônimo de aplicação. 
instrucionais no processo de aprendizagem de formas linguísticas num ambiente comunicativo (DUTRA, 2015), visto que há uma relação inversamente proporcional entre os índices de produtividade das formas-alvo e os valores correspondentes à aplicação das estruturas não metas. Nesta investigação, analisamos e discutimos o papel da intervenção pedagógica na redução do uso de transferência linguística e de outros casos de estruturas alternativas empregadas no processo de aprendizagem do presente do subjuntivo do espanhol. Os eixos temáticos que nortearam o presente estudo foram os que seguem: efeitos e durabilidade da intervenção instrucional, transferência linguística.

Para fins de orientação, a seguir, apresentamos o modo como organizamos este artigo. Após a introdução, apresentamos a fundamentação teórica. Na sequência, mostramos a metodologia, a qual é seguida da análise e discussão dos resultados. Por último, trazemos as considerações finais.

\section{FUNDAMENTAÇÃO TEÓRICA}

Nesta seção, abordamos, inicialmente, o uso do presente do subjuntivo e do futuro do subjuntivo em espanhol e em $\mathrm{PB}$, respectivamente. Na sequência, é explorado o papel da língua materna (doravante, LM) do aprendiz na aprendizagem de uma LE. Por fim, são explicitadas questões sobre a IFF.

\subsection{0 presente do subjuntivo em espanhol e o futuro do subjuntivo em português brasileiro}

A fim de analisarmos a transferência linguística do $\mathrm{PB}$, no processo de aprendizagem do presente do subjuntivo do espanhol, a seguir, tratamos do presente do subjuntivo nessa língua e do futuro do subjuntivo em $\mathrm{PB}$, a partir de abordagens descritivas.

No que diz respeito ao tratamento descritivo do presente do subjuntivo em espanhol, Bosque e Demonte (1999) explicam o seguinte: "Quando o tempo da oração principal pertence à esfera do presente, na oração subordinada aparece o presente do subjuntivo se o conector for cuando e o tempo principal indicar posterioridade" (BOSQUE; DEMONTE, 1999, p. 3119).

Nas situações em que o verbo da oração principal aparece em futuro perfecto, obtemos a leitura de simultaneidade entre o estado de coisas que supõe o futuro perfecto e o tempo do evento da subordinada, como em Pepe babrá acabado la tesis cuando lleguen sus padres. Como neste caso o evento principal "habrá terminado" precede o 
evento subordinado "lleguen", podemos compreender que há simultaneidade entre o estado que supõe o resultado do evento principal e o evento subordinado.

Conforme Bosque e Demonte (1999, p. 3313), as orações introduzidas por cuando se comportam, de maneira geral, de forma semelhante ao restante das orações temporais. Estarão no indicativo se designam eventos factuais (passados, presentes ou habituais) e no subjuntivo se remetem a contextos posteriores e não factuais, como em No encontrará a nadie cuando llegue.

Os autores também se referem ao contraste entre indicativo e subjuntivo ${ }^{3}$, na medida em que o tempo da oração principal pode assumir um valor de presente habitual ou de futuro, no caso de Cuando nos habla/hable, así, le damos un cachete (BOSQUE; DEMONTE, 1999, p. 3313). Com o indicativo, a oração subordinada designa um fato habitual (e a conjunção cuando assume um valor semelhante ao da locução siempre que); com o subjuntivo, ao contrário, a oração se refere a uma eventualidade futura e assume um valor próximo ao das orações condicionais ${ }^{4}$. Da mesma maneira, Matte Bon (1995) considera incompatível que se use o presente do subjuntivo com ideia de passado. ${ }^{5}$

Passemos, agora, ao uso do futuro do subjuntivo em PB. Com base numa abordagem descritiva ${ }^{6}$, de acordo com Castilho (2010), do ponto de vista sintático,

3. Veidmark e Aguiar (1991) analisam a substituição do subjuntivo pelo indicativo no espanhol em contextos em que a gramática normativa prevê o uso do primeiro modo. $\mathrm{O}$ estudo tem como foco a realização de orações relativas com antecedentes não específicos por costa-riquenhos. Segundo os autores, há evidências de uma possível mudança em direção ao desaparecimento do subjuntivo na língua espanhola.

4. Kanwit e Geeslin (2014) apontam para a variação que ocorre nas orações adverbiais com cuando, después de que e basta que. Segundo mostram os autores, nem sempre uma oração no subjuntivo com estes operadores será interpretada pelos falantes como fazendo referência a um fato futuro, ao mesmo tempo em que nem sempre uma oração no indicativo com estes operadores será interpretada como fazendo referência a um fato habitual. Kanwit e Geeslin também discutem a interpretação dos modos subjuntivo e indicativo nestes contextos por falantes não nativos.

5. A descrição feita nesta seção não pretende ser exaustiva. Como esclarece Fábregas (2014), "o subjuntivo tem um grande número de diferentes usos, o que torna difícil agrupá-los sob um único rótulo" (FÁBREGAS, 2014, p. 27). Apesar disso, autores como Vesterinen e Bylund (2013) buscam uma abordagem explicativa que dê conta de unificar os diferentes contextos de usos do subjuntivo. Os autores fazem isto a partir da perspectiva da gramática cognitiva. Como nosso objetivo aqui é estritamente descritivo, não nos alongaremos na discussão desta proposta.

6. Da mesma forma que ocorre em espanhol, em PB também há estudos que mostram variação entre subjuntivo e indicativo. Conforme Mollica (2003), "estudos sobre a fala vêm mostrando que o português brasileiro atual lança mão de muitas formas verbais nem sempre previstas pela tradição da norma para exprimir o modo subjuntivo e o tempo futuro" (MOLLICA, 2003, p. 121). Pimpão (2015) faz um levantamento de uma série de estudos que têm por foco tal variação. Já Bittencourt (2012) analisa a variação que pode ocorrer especificamente no futuro do subjuntivo, mostrando que algumas formas verbais podem sofrer regularização (compuser x compor) em função das semelhanças entre esta estrutura verbal e o infinitivo flexionado. 
o subjuntivo, no $\mathrm{PB}$, predomina nas sentenças subordinadas. Em relação às subordinadas temporais com quando, expressam um tempo anterior, simultâneo ou posterior ao da matriz, no caso de Quando você chegar, eu já terei comido toda a sobremesa (CASTILHO, 2010, p. 379). Semanticamente, o subjuntivo expressa um estado duvidoso de coisas. O futuro (simples ou composto) do subjuntivo "expressa posterioridade problemática, em sentenças subordinadas: Só virei a perguntar se ele previamente tiver demonstrado disposição para responder" (CASTILHO, 2010, p. 435).

Ao descrever as orações temporais, Moura Neves (2000) afirma que "o modo subjuntivo pode ser usado na oração temporal iniciada por quando, o que ocorre especialmente no futuro, resultando em expressão de eventualidade" (MOURA NEVES, 2000, p. 792). A autora explicita ainda que a oração principal leva o verbo no presente do indicativo ou no futuro do indicativo e/ou do subjuntivo, mas não no presente do subjuntivo.

Cabe mencionar que, como afirmam Ilari e Basso (2009), "o paradigma de conjugação dos verbos portugueses inclui, como se sabe, alguns 'tempos' que inexistem nas outras línguas latinas, entre eles o futuro do subjuntivo ${ }^{7}$ (se en fizer, quando eu puder) e o infinitivo flexionado (trouxe o carro para nós consertarmos)" (ILARI; BASSO, 2009, p. 100). Como mostram Camara Jr. (1979) e Mattos e Silva (2006), o futuro do subjuntivo não existia em latim. Tal estrutura verbal, em português, teve origem nos seguintes modos e tempos do latim, conforme Mattos e Silva (2006): futuro perfeito do indicativo, presente perfeito do subjuntivo e pretérito imperfeito do subjuntivo. ${ }^{8}$

A partir da comparação do uso do modo subjuntivo nas línguas em exame, é possível verificarmos que o $\mathrm{PB}$ requer o uso do futuro do subjuntivo em contextos em que o espanhol, diferentemente, prevê o uso do presente do subjuntivo, como em Quando eu tiver dinbeiro suficiente, comprarei um carro/Cuando tenga dinero suficiente, voy a comprar un coche. Neste caso, podemos constatar que a frase anterior, em PB, e sua possível "tradução", em espanhol, remetem a subordinadas adverbiais introduzidas por quando/cuando, com orações principais que indicam um evento futuro: no que diz respeito à norma culta, em português, tal estrutura levará o verbo da oração

7. Comrie e Holmback (1984) mencionam a existência do futuro do subjuntivo no espanhol, mas qualificam seu uso como "decididamente arcaico" (COMRIE; HOLMBACK, 1984, p. 213).

8. De acordo com a proposta de análise de Camara Jr. (1970), o futuro do subjuntivo, levando em consideração a norma padrão do $\mathrm{PB}$, é constituído pelo radical do verbo, seguido de sua vogal temática, da desinência modo-temporal (-r para a $1^{\mathrm{a}}$ e a $3^{\mathrm{a}}$ pessoa do singular e para a $1^{\mathrm{a}}$ e a $2^{\mathrm{a}}$ pessoa

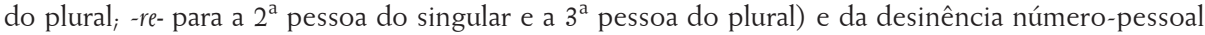
$\left(\varnothing\right.$ para a $1^{\mathrm{a}}$ e a $3^{\mathrm{a}}$ pessoa do singular ${ }_{i}-s$ para a $2^{\mathrm{a}}$ pessoa do singular, ${ }^{-}$-mos para a $1^{\mathrm{a}}$ pessoa do plural -des para a $2^{\mathrm{a}}$ pessoa do plural; e $-m$ para a $3^{\mathrm{a}}$ pessoa do plural). 
subordinada para o futuro do subjuntivo; enquanto, em espanhol, neste ambiente linguístico, ocorrerá o presente do subjuntivo na oração subordinada.

A seguir, apresentamos questões conceituais a respeito da transferência linguística e da instrução com foco na forma.

\subsection{0 papel da língua materna na aprendizagem da segunda língua/ língua estrangeira}

A transferência é a influência que resulta das semelhanças e das diferenças entre a língua-alvo e qualquer outra língua que tenha sido adquirida anteriormente (ODLIN, 1989). A nova noção de transferência linguística inclui um conjunto de comportamentos, processos ou restrições que estão relacionados ao uso do conhecimento prévio da LM ou de outras línguas estrangeiras (SELINKER, 1992). Nessa linha, Koda (1997) afirma que as estratégias cognitivas envolvidas na compreensão e produção de orações são determinadas pelas propriedades estruturais específicas de cada língua. No caso do brasileiro aprendiz de espanhol, uma vez estando consciente da proximidade entre essa língua e o PB, ele ativaria procedimentos similares de processamento de ambas as línguas (VILLALBA, 2002). Portanto, o princípio da semelhança entre a LM e a LE/L2 seria um dos fatores facilitadores da aquisição (KODA, 1997).

Conforme resultados de estudos na ASL (CRUZ, 2001; VILLALBA, 2002; BOÉSSIO, 2003; SCHROEDER, 2004), línguas tipologicamente próximas parecem favorecer a transferência linguística da LM para a LE/L2. Contudo, existe a necessidade de que se tenha cautela quanto à semelhança, entendida como fator facilitador de acesso e aquisição de língua estrangeira, visto que, no caso do aprendiz brasileiro de espanhol, parece que a dificuldade está relacionada à falsa semelhança e, primordialmente, à indefinição da dicotomia semelhança/falsa semelhança no que se refere à indeterminação dos limites linguísticos entre o PB e o espanhol (VILLALBA, 2002).

A transferência é um processo que pode envolver o conhecimento prévio da

LM, bem como de outras línguas conhecidas, para suprir lacunas de conhecimento linguístico na língua-alvo, tendo em vista a percepção de distância entre as línguas envolvidas, e mais especificamente da estrutura requerida durante o processo de interação. Nesse sentido, a transferência é compreendida como estratégia compensatória da insuficiência de conhecimento da língua-alvo que está restrita à percepção de distância por parte do aprendiz entre a LM e a L2 (OTTONELLO, 2004). 
Na literatura de ASL (CANALE, 1983), há menção ao uso da LM como estratégia de comunicação (doravante, EC), a qual pode ser compreendida como mecanismos utilizados para resolver problemas comunicativos (GÓMEZ, 2004). Nesse sentido, a EC (DORNYEI; KORMOS, 1998) revela a utilização da biografia linguística do aprendiz, no processo de aquisição de L2, conforme podemos observar a seguir:

i) utilização de uma palavra da língua materna, com ajustes fonológicos ou morfológicos à L2/LE, classificada como estrangeirismo;

ii) utilização de uma palavra da língua materna com a pronúncia dessa língua ou uma palavra de uma terceira língua com a pronúncia da terceira língua na L2/LE, denominada mudança de código;

iii) mudança de especificações da gramática através da generalização excessiva de regras na L2/LE ou transferência no uso de regras da L1 para a L2/LE, chamada substituição gramatical.

Pesquisas têm apontado resultados que corroboram os casos supramencionados a respeito da influência da LM na aquisição/aprendizagem de espanhol por brasileiros. No que tange a essa questão, podemos observar casos de estrangeirismo ${ }^{9}$ no estudo de Villalba (2002), que trata acerca da transferência linguística e dos indícios de fossilização no conhecimento lexical em espanhol de universitários brasileiros. Os resultados dessa investigação indicaram o uso de "arrumación" (grupos básico e intermediário), em vez de "ordenación", e de "hesitación" (grupo avançado), no lugar de "vacilación", o que sugere, do ponto de vista morfológico, o emprego da base lexical do PB acompanhado de acréscimo de monemas ${ }^{10}$ do espanhol. Além disso, houve a produção de palavras em português em grupos de proficiências distintas. Nesse sentido, ocorreu a produção da palavra "panela" (no grupo básico), bem como a realização de "pia" e "desespero", respectivamente, nos grupos intermediário e avançado. Esses casos remetem a empréstimos classificados como mudança de código.

Quanto à substituição gramatical como EC, o estudo de González (1994) apontou transferência referente à aprendizagem dos clíticos do espanhol representada por supergeneralização de regras, processo no qual, segundo a pesquisadora, o clítico apareceu, de maneira indevida, conforme podemos observar

9. Villalba classifica o caso de estrangeirismo como 'espanholização'.

10. Conforme Kehdi (2007, p. 68), "A. Martinet designa as unidades mínimas significativas como monemas, reservando para os morfemas lexicais a denominação de lexemas e, para os gramaticais, a de morfemas". 
no excerto ${ }^{11}$ a seguir: Enrique se decepcionó mucho porque no pudo obtener el empleo. Entonces yo se lo dije a él que Santiago había obtenido el puesto. Nesse exemplo, é possível constatarmos que se apresenta antecipadamente o clítico acusativo lo para se referir à oração substantiva, ou seja, antes da produção da oração, em função de objeto direto (trecho em negrito), isto é, há a ocorrência do objeto direto catafórico (GONZÁLEZ, 1994).

$\mathrm{Na}$ sequência apresentamos a seção alusiva à instrução com foco na forma.

\subsection{Instrução com foco na forma}

A IFF, inserida num contexto comunicativo e significativo para o aluno, privilegia tanto a comunicação quanto a acuidade; inclui, respectivamente, atenção ${ }^{12}$ ao significado ${ }^{13}$ e à forma (HOWATT, 1984). Spada (1997, p. 73) define IFF como "qualquer esforço pedagógico que é usado para chamar implícita ou explicitamente a atenção do aprendiz para forma da língua. Isso pode incluir o ensino da língua por meio de regras gramaticais e/ou reações para erros do aprendiz (feedback corretivo) ".

Spada (1997) explica que, na IFF, eventos pedagógicos ocorrem em abordagens baseadas no significado em que o foco da atenção dos aprendizes a elementos linguísticos ocorre espontaneamente ou de modo planejado, ao passo que a IFF com base em Long (1991) restringe-se a eventos pedagógicos baseados no significado em que a atenção dos estudantes a aspectos linguísticos sucede em resposta à percepção de necessidades comunicativas. Em outras palavras, a IFF, a partir da ótica de Long (1991), inclui apenas ações pedagógicas incidentais, ao passo que a IFF na visão de Spada (1997) abrange práticas pedagógicas de natureza predeterminada e não planejada.

A palavra forma é considerada em contexto mais amplo (DOUGHTY; WILLIAMS, 1998). Logo, há suporte de que forma não é sinônimo de gramática, visto que inclui todos os níveis e componentes da língua, ou seja, ultrapassa os níveis da gramática (sintaxe e morfologia), envolvendo, por exemplo, fonologia e léxico. Quanto ao modo de instrução, a forma-alvo pode fazer parte de tratamento instrucional por meio de seleção prévia (instrução planejada) ou instantânea (instrução não planejada).

11. Extraído de González (1994).

12. Capacidade limitada (atenção seletiva), necessária para a aprendizagem, que controla o acesso à consciência e a ação (SCHMIDT, 2001).

13. Por significado semântico podemos compreender os significados de itens lexicais ou aspectos gramaticais específicos, ao passo que o sentido pragmático abrange os significados contextualizados que emergem nos atos de comunicação (ELLIS, 2005). 
Há evidências a favor da instrução explícita que envolve metalinguagem e claros sinais para o aprendiz de que há uma maneira certa e errada para dizer ou escrever algo na língua-alvo (SPADA, 2010). Estudos empíricos (NORRIS; ORTEGA, 2000, SPADA, 1997; 2010; SPADA; TOMITA, 2010) têm apontado a eficácia da IFF na aquisição de segunda língua. Outra argumentação a favor da instrução explícita vem de estudos cujos pesquisadores trataram dos efeitos instrucionais relacionados à forma-alvo e à redução de transferência linguística. O trabalho de Loose (2006) tratou do papel da instrução explícita na aquisição, por falantes de português, de estruturas fonológicas e morfológicas, mais especificamente a lateral pós-vocálica /1/, o verbo gustar e o artigo neutro lo, entre aprendizes de espanhol pertencentes a dois contextos de ensino: universidade e escola regular. Os dados foram coletados em três etapas. $\mathrm{Na}$ fase pós-instrucional, os testes foram aplicados dois meses após o encerramento do período de instrução e seis meses após a segunda coleta de dados. Os resultados indicaram que houve diferença na aquisição das estruturas morfológicas e fonológicas em estudo, visto que a instrução explícita produziu efeitos benéficos, de caráter imediato e duradouro, na aquisição de gustar e de lo, o que não ocorreu com a lateral pós-vocálica [1]. Os dados também sugeriram que a instrução explícita reduziu a interferência da LM na aprendizagem das formas-alvo.

Dutra (2015) examinou os efeitos e a durabilidade do tratamento instrucional na aquisição/aprendizagem dos clíticos de terceiras pessoas do espanhol, caracterizados como formas simples e complexas, na modalidade de uso espontâneo e controlado, por universitários brasileiros com menos e mais tempo de estudo da língua-alvo. A pesquisa contou com 10 estudantes de um Curso de Letras. Os dados foram obtidos por meio de pré-teste, pós-teste imediato e pós-teste postergado. Os resultados apontaram que o tratamento instrucional ocasionou a redução da transferência linguística do PB para o espanhol na aprendizagem das formas-alvo. Além disso, os dados sugeriram que a intervenção pedagógica produziu avanço e efeitos duráveis, respectivamente, das formas simples e complexas que seguem em processo de aquisição entre os alunos participantes.

Além da instrução explícita, professores de L2 e/ou pesquisadores na ASL podem utilizar uma variedade de técnicas ou tarefas com a tentativa de ocasionar a percepção de aspectos linguísticos específicos, por parte dos aprendizes, no insumo recebido. Essas técnicas correspondem a estratégias pedagógicas ${ }^{14}$.

Independentemente do tipo de instrução, é possível que o professor faça uso de tarefas no tratamento instrucional. Nesse sentido, a instrução pode ser baseada na compreensão (IBC, doravante) ou na produção (IBP, doravante). Em razão de

14. Sinônimo de estratégias de ensino. 
delimitação, tratamos da IBP com base na Hipótese da Produção Compreensível, a partir da qual é possível examinar as possíveis funções ${ }^{15}$ que o output ${ }^{16}$ (produção oral/escrita) pode exercer no processo de aprendizagem de uma L2 (SWAIN, 1995; 1998; 2005).

O esforço do estudante quanto à percepção do novo traço linguístico e da diferença entre a sua representação na língua de aprendiz e o insumo na língua-alvo refere-se à Hipótese da Percepção da Lacuna (Noticing the Gap Hypothesis). Nesse sentido, é possível que os estudantes se tornem conscientes de um problema linguístico, apesar de não haver feedback explícito ou implícito, uma vez que podem perceber a lacuna em seu próprio conhecimento linguístico no momento em que encontram um problema durante a tentativa de produção na língua-alvo (SWAIN, LAPKIN, 1995).

A produção dos estudantes na aprendizagem de uma L2 também pode estar relacionada à formulação e à comprovação de hipóteses sobre como funcionam novas formas linguísticas (SWAIN, 1995; 1998). O feedback adotado pelo professor propicia condições para que os estudantes refutem estruturas que fogem às regras da L2. Swain (2005) explica que o processo em que os aprendizes modificam sua produção linguística em reposta ao feedback faz parte da aprendizagem. Entretanto, conforme essa pesquisadora, não se tem demonstrado que a produção linguística modificada (reprocessada) prediz aprendizagem. Deste modo, a modificação da produção linguística pode contribuir para o processo de aquisição da L2, contudo não a garante (SWAIN, 1995; 1998).

No presente estudo, de um lado, o efeito instrucional envolve, do pré-teste em comparação ao pós-teste imediato, em curto prazo, a redução dos índices de não aplicação do presente do subjuntivo do espanhol. Por outro lado, a durabilidade alude, em médio prazo, à estabilidade da diminuição dos índices de não aplicação do presente do subjuntivo obtido em curto prazo. Na sequência, apresentamos a metodologia.

\section{METODOLOGIA}

Deste estudo ${ }^{17}$, de caráter intervencionista, fizeram parte 12 estudantes do Curso de Letras Espanhol/Português e respectivas Literaturas de uma universidade

15. Neste estudo, não incluímos a função de meta-fala.

16. Optamos pelo uso de "produção" ou "produção linguística" em vez de output.

17. O trabalho aqui apresentado é um recorte ampliado de Moraes (2014), em que a autora analisou, além de cuando, as estruturas com aunque e donde. 
A aprendizagem do presente do subjuntivo do espanhol em orações temporais ...

privada, localizada no interior do Rio Grande do Sul. Os objetivos que nortearam o presente estudo foram:

(i) verificar os efeitos e a durabilidade da intervenção instrucional, a partir de dados referentes à não aplicação do presente do subjuntivo do espanhol, por meio da observação da redução dos índices alusivos a estruturas linguísticas alternativas;

(ii) averiguar a existência de casos de transferência linguística na aprendizagem de aspecto linguístico em caso de línguas próximas, através da análise de dados de pré-teste.

As hipóteses correspondentes aos objetivos supracitados são as que seguem:

(i) o tratamento instrucional adotado nesta pesquisa possibilitará efeitos duráveis (LOOSE, 2006; DUTRA, 2015);

(ii) casos de transferência linguística estarão presentes na produção dos participantes deste estudo (VILLALBA, 2002, 2004; BOÉSSIO, 2003; LOOSE, 2006; DUTRA, 2015).

A seleção dos participantes foi pautada nos seguintes critérios: não ter tido contato formal com o espanhol antes do ingresso no curso de Letras; não ter participado de intercâmbio e tampouco ter realizado viagens para países de fala espanhola. Para a obtenção de dados, esta pesquisa abrangeu aplicação do pré-teste, fornecimento do tratamento instrucional, aplicação do pós-teste imediato e coleta de dados por meio do pós-teste postergado. No que concerne ao intervalo entre a intervenção instrucional e as fases pós-instrucionais, ocorreu a coleta de dados, em curto/médio prazos, respectivamente, uma e sete semanas após a finalização da intervenção pedagógica.

Quanto à intervenção pedagógica, no primeiro dia, houve aulas expositivas sobre os modos indicativo e subjuntivo, suas diferenças e usos, acompanhadas de exemplos e da sua produção por parte dos alunos-participantes. Ocorreram também explicações sobre as diferenças do presente do subjuntivo/futuro do subjuntivo entre o espanhol e o PB. Nessa fase de tratamento instrucional, foram aplicadas tarefas (preenchimento de lacunas, elaboração de respostas orais a perguntas). A segunda aula da intervenção instrucional foi destinada à fixação do presente do subjuntivo do espanhol por meio de tarefas de produção oral e tarefas de produção escrita, que foram realizadas na plataforma Edmodo. Os pós-testes imediatos e os pós-testes postergados foram aplicados, respectivamente, uma e sete semanas após o término do tratamento instrucional, como foi mencionado anteriormente. 
Os dados foram oriundos de testes de produção oral (perguntas controladas, descrição de imagem e criação de história) e de testes de produção escrita (preenchimento de lacunas, descrição de imagem e criação de história). Vale destacarmos que nos centramos apenas nos dados provenientes de não aplicação do presente do subjuntivo a partir de orações temporais (Cuando + ideia de futuro + oração principal).

Para fins de análise, recorremos ao Teste Normal Padrão para comparação de proporções, a fim de verificar se as diferenças nas porcentagens encontradas eram significativas. Este teste permite a verificação de duas hipóteses: a hipótese nula, segundo a qual há igualdade nas proporções, e a hipótese de acordo com a qual as proporções são diferentes. Em um nível de significância de 5\%, a confirmação da hipótese nula é registrada com um resultado de $Z$ entre $-1,96$ e 1,96. Os resultados de $Z$ que estiverem fora deste intervalo permitem a rejeição da hipótese nula e, consequentemente, a confirmação de que há uma diferença significativa entre as proporções. A seguir, apresentamos a análise e discussão dos resultados.

\section{ANÁLISE E DISCUSSÃO DOS RESULTADOS}

A seguir, inicialmente, realizamos, de maneira qualitativa, nossa análise e discussão dos resultados, por meio da indicação de casos oriundos das formas alternativas que são utilizadas no lugar da forma-alvo em exame nesta investigação. Posteriormente, apresentamos uma análise quantitativa, a partir dos índices de aplicação das formas alternantes, ao longo das etapas de obtenção de dados, pautada no Teste Normal Padrão.

A fim de evidenciarmos que as produções linguísticas dos indivíduos deste estudo, em fase anterior ao tratamento pedagógico, apresentavam inadequações no que tange ao uso das formas-alvo, apresentamos os exemplos a seguir:

(1) Cuando mi bermano comprar la cbaqueta....

(2) Cuando estiver en Barcelona...

(3) Cuando volver a viajar...

(4) Cuando salirmos del cine...

A partir dos exemplos anteriores, oriundos do pré-teste, na oração subordinada temporal com ideia de futuro, assinalamos que, de um lado, existem formas verbais que sugerem o uso do verbo em PB, como em (1) e (2). Tais casos indicam exemplos de empréstimo do $\mathrm{PB}$ no processo de comunicação em espanhol, 
mais especificamente remetem à mudança de código. Este tipo de EC parece não se limitar a grupos de estudantes de nível básico, visto que os participantes do presente estudo eram estudantes do nível intermediário. Essa tendência corrobora os resultados da pesquisa de Villalba (2002), os quais indicaram a ocorrência de mudança de código, no nível lexical, entre grupos de maior proficiência.

Entretanto, por outro lado, há formas verbais que fogem à norma do espanhol, como em (3) e (4) e que aludem a casos de transferência linguística como EC. O conhecimento linguístico prévio dos alunos-participantes no que se refere às orações temporais não factuais do PB parece influenciar o processo de aprendizagem das orações temporais dessa natureza em espanhol, uma vez que, nesse contexto linguístico, aquela língua requer o uso do futuro do subjuntivo em ambientes em que o espanhol, diferentemente, prevê o uso do presente do subjuntivo, como no caso de Cuando mi hermano compre la chaqueta, me la prestará. A respeito desta questão, observemos a afirmação a seguir:

A utilização de quando com idéia de futuro é motivo de transferência indevida por alunos
brasileiros aprendizes de espanhol. Os aprendizes utilizam a construção do Português, quando
deveriam utilizar o presente do subjuntivo que expressa essa ideia de futuro no Espanhol. No
Português, é comum a construção: "Quando chover eu estudo". No Espanhol, essa construção
não seria possível, e sim: "Cuando llueva, estudio" (BOÉSSIO, 2003, p. 48, grifo do autor).

Como mencionamos anteriormente, o português apresenta paradigma de conjugação de alguns 'tempos', entre os quais o futuro do subjuntivo, que inexistem nas outras línguas latinas (ILARI; BASSO, 2009), ou seja, essa forma verbal é específica do português em comparação às outras línguas neolatinas. Por conseguinte, as construções de (3) e (4) sugerem o acesso, por parte dos alunosparticipantes, em contexto linguístico específico, à regra referente à constituição da forma verbal que corresponde, em PB, ao futuro do subjuntivo, ou seja, ocorre uma EC na modalidade de substituição gramatical.

Nos exemplos sob análise, há indícios de testagem de hipótese acerca da equivalência da regra da forma verbal do PB no espanhol, que serve como EC, visto que o apoio na língua materna permite um mínimo de comunicabilidade (VILLALBA, 2002). O emprego do futuro do subjuntivo ${ }^{18}$, em espanhol, por aprendizes brasileiros ocorre em função da proximidade dessa língua com o PB (BOÉSSIO, 2003). Neste estudo, a proximidade tipológica entre as línguas

18.Boéssio (2003) utiliza o termo infinitivo flexionado tanto para referir-se a contextos linguísticos que o requerem, como em orações finais, quanto para remeter a ambientes que exigem o futuro do subjuntivo, o que sugere uma opção terminológica da autora. Contudo, neste estudo, utilizamos o futuro do subjuntivo quando a estrutura empregada pelo aluno corresponderia, em $\mathrm{PB}$, a esta forma verbal. 
envolvidas sugere não apenas o acesso à regra do futuro do subjuntivo do $\mathrm{PB}$, nos excertos (3) e (4), mas também o emprego de estrutura verbal propriamente dita dessa língua, como em (1) e (2).

A proximidade interlinguística não parece ser um fator facilitador do processo de ASL, uma vez que, segundo Villalba (2002), a dificuldade está relacionada à falsa semelhança e, principalmente, à indefinição da dicotomia semelhança/falsa semelhança no que se refere à indeterminação dos limites linguísticos entre o PB e o espanhol, como mencionamos anteriormente. $\mathrm{O}$ uso do futuro do subjuntivo em espanhol parece ocorrer em virtude da ausência da observação das devidas equivalências que se efetuam no espanhol, o que ocasiona uma tradução literal do PB no processo de produção em espanhol (CRUZ, 2001).

No tocante a esta questão, de modo similar ao que ocorre com o brasileiro no processo de aquisição dos clíticos de terceiras pessoas do espanhol (DUTRA, 2015), é possível conjecturarmos que (em função da ausência de percepção dos limites de proximidade e de distância entre o PB e o espanhol, nos distintos níveis linguísticos de ambas as línguas, mais especificamente no emprego do presente do subjuntivo do espanhol, em orações temporais) o aprendiz brasileiro, pautado na semelhança interlinguística, parece recorrer ao seu conhecimento prévio da LM durante o processo de aprendizagem do espanhol como LE/L2 por supor que essa área da gramática é similar em ambas as línguas. Dito isto, ações pedagógicas que permitam a percepção por parte dos aprendizes no que tange a convergências e divergências estruturais, no caso de línguas próximas (LM e LE) parece surtir efeitos benéficos (LOOSE, 2006; MORAES, 2014; DUTRA, 2015) no processo de ensino-aprendizagem da língua-alvo, conforme podemos observar mais adiante.

Independentemente da categoria da forma alternativa selecionada pelos aprendizes, podemos observar que existe uma variabilidade no que tange à sua seleção, e, consequentemente, à sua aplicação em orações temporais para expressar eventos que não ocorreram.

A seguir, apresentamos outros casos de construções referentes a orações subordinadas temporais produzidas pelos participantes deste estudo:

(5) Cuando saiba/supa la notícia...

(6) Cuando estoy en Barcelona....

(7) Cuando mi hermano compró la chaqueta...

(8) Cuando caminase por la calle...

Os casos alusivos aos excertos supracitados (de 5 a 8) também sugerem oscilação de estratégias inadequadas utilizadas no lugar do presente do subjuntivo 
A aprendizagem do presente do subjuntivo do espanhol em orações temporais ...

do espanhol, em orações temporais, ou seja, há uma série de formas alternativas que não condizem com os usos do espanhol nesse contexto linguístico. No caso do excerto (5), o interpretamos como erro de conjugação do verbo, visto que houve a tentativa de conjugar corretamente, ou pela relação com o português (no caso de saiba, como no exemplo), ou de aproximação (no caso de supa no lugar de sepa, como no exemplo). Com relação ao excerto (6), no lugar do presente do subjuntivo do espanhol com cuando, há o emprego do presente do indicativo. É válido relembrarmos que, quando a oração subordinada com o indicativo, como em Cuando nos babla, así, le damos un cachete, assume um valor equivalente a siempre que, ela expressa, desse modo, habitualidade (BOSQUE, DEMONTE, 1999). Contudo, no caso de que a oração subordinada esteja no subjuntivo, como em Cuando nos bable, así, le damos un cacbete, ela faz referência a um evento futuro e assume um valor similar ao das orações condicionais (BOSQUE; DEMONTE, 1999). A partir do exposto, no excerto (6), podemos supor que não está claro para o aluno que o uso do presente do indicativo com ideia de futuro implica uma ideia de habitualidade.

Também podemos constatar a utilização de verbo no passado e do pretérito imperfecto de subjuntivo, respectivamente nos casos (7) e (8), no ambiente linguístico referido. Quanto a esses últimos casos, podemos hipotetizar o seguinte: há a existência de dúvida no que tange à correlação temporal entre a oração subordinada temporal e a oração principal, o que sugere desconhecimento da regra de uso das orações temporais em espanhol com ideia de evento no futuro. $\mathrm{O}$ uso de verbo no passado, mais especificamente do pretérito indefinido, em espanhol, em orações temporais, requer, por exemplo, o emprego de verbo no mesmo tempo e modo, como em Ayer, cuando llegué a casa, llamé a Eduardo, ou o uso do pretérito pluscuamperfecto, no caso de Cuando llegué ya babían terminado, segundo apresentam, respectivamente, Castro (2003) e Santos (1993). Há indicação do uso do pretérito imperfecto de subjuntivo, em orações temporais, em espanhol (SANTOS, 1993), contudo é válido destacarmos que a ideia nesse caso não é a de futuro.

No que concerne aos casos supracitados, na língua do aprendiz dos participantes desta investigação, é possível observarmos testagens de hipóteses que parecem revelar a transferência linguística propriamente dita, fenômeno compreendido como estratégia de comunicação (VILLALBA, 2002; OTTONELLO, 2004), tendo em vista o conhecimento linguístico insuficiente na língua-alvo e a percepção dos alunos no que tange à distância/ proximidade entre a LM e a LE/L2, entre outros aspectos. Além disso, cabe destacarmos que casos de utilização parcial de palavras da LM com ajustes fonológicos ou morfológicos, com base nas regras da LE/L2 (estrangeirismo), o uso de palavras da LM (mudança de código), bem 
como situações de supergeneralização e/ou uso de regras da LM em construções da língua-alvo (substituição gramatical) remetem a casos de EC relacionados à influência da LM.

No tocante à variabilidade de aplicação de formas alternativas no lugar do presente do subjuntivo em orações temporais com ideia de futuro, as evidências apresentadas podem caracterizar a língua do aprendiz dos participantes deste estudo como instável, em fase pré-intervenção instrucional, corroborando resultado de outro estudo (CRUZ, 2001) referente à aprendizagem do sistema pronominal do espanhol.

Na sequência tratamos de analisar e discutir os dados a partir dos índices de não aplicação da forma-alvo ao longo das etapas de coleta de dados.

Nossa hipótese de que a intervenção pedagógica traria efeitos benéficos e duráveis sobre a aplicação das formas não alvo, ao longo das etapas pós-instrucionais, foi confirmada.

A seguir, no Gráfico 1, indicamos os índices de produtividade das formas alternativas, que são empregadas no lugar do presente do subjuntivo do espanhol, ao longo das três etapas de coleta de dados, com o intuito de averiguarmos os efeitos e a durabilidade do tratamento instrucional sobre a diminuição das estruturas referentes à não aplicação do presente do subjuntivo.

Gráfico 1. Não aplicação do presente do subjuntivo nas etapas de coleta

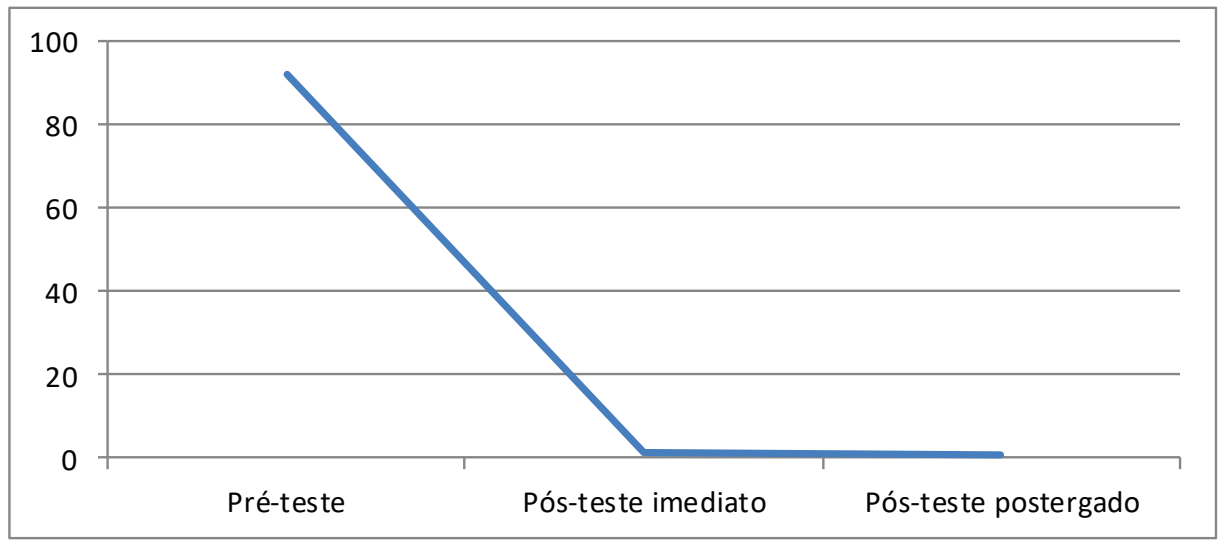

Fonte: Autores (2018)

A partir do Gráfico 1, podemos observar que houve uma queda acentuada na não realização do presente do subjuntivo entre o pré-teste $(92,20 \%)$, em que, de um total de 154 ambientes linguísticos passíveis de ocorrência da forma-alvo, 
A aprendizagem do presente do subjuntivo do espanhol em orações temporais ...

houve 142 casos de não aplicação do presente do subjuntivo do espanhol, e o pós-teste imediato, em curto prazo, com apenas dois casos referentes a formas alternantes, isto é, um percentual de 1,31\%, de um universo de 152 possibilidades de ocorrências, o que indica efeito instrucional sobre a aprendizagem da formaalvo. A significância deste resultado é ratificada pelo Teste Normal Padrão, com um resultado de $Z=15,92$.

O resultado do pós-teste postergado $(0,66 \%)$, com a frequência de um caso de não aplicação da forma verbal pretendida, em médio prazo, de um total de 150 contextos linguísticos propícios à sua produtividade, aponta para a durabilidade deste efeito. Embora tenha havido uma queda da não realização do presente do subjuntivo entre o pós-teste imediato e o pós-teste postergado, o que atesta um aumento da realização desta forma verbal entre uma etapa de coleta e outra, o Teste Normal Padrão mostra que esta diferença percentual não é estatisticamente relevante $(Z=0,56)$.

Desta forma, com base nos resultados estatísticos, não podemos afirmar que houve uma intensificação dos efeitos de IFF entre o pós-teste imediato e o pós-teste postergado, ou seja, não é possível asseverar que houve a continuidade da redução da produtividade das formas linguísticas referentes à não aplicação no pós-teste postergado. Esta questão parece estar relacionada à ligeira diferença de diminuição de ocorrências das formas não-alvo entre as etapas pós-instrucionais, visto que o número de contextos passíveis de ocorrência do presente do subjuntivo do espanhol é praticamente idêntico, nas fases posteriores à intervenção pedagógica, com a diminuição unicamente de dois casos de não produtividade da forma-alvo para um caso entre o pós-teste imediato e pós-teste postergado, o que nos permite sugerir a durabilidade dos efeitos instrucionais. Entretanto, cabe destacarmos que existe uma relação inversamente proporcional entre a produtividade da forma-alvo e a aplicação das estruturas alternativas utilizadas. Portanto, a indicação da diminuição da não aplicação do presente do subjuntivo sugere o aumento da produtividade da formaalvo ao longo das etapas pós-instrucionais. Isso significa que, após a administração da intervenção pedagógica, houve a redução das estruturas alternativas. Tal efeito se manteve estável na última etapa pós-instrucional.

Para fins elucidativos, apresentamos, na sequência, o Gráfico 2, no qual representamos os índices referentes aos dados de aplicação do presente do subjuntivo do espanhol, com base na diminuição da não produtividade dessa forma linguística, conforme indicado anteriormente. 
Gráfico 2. Aplicação do presente do subjuntivo nas etapas de coleta

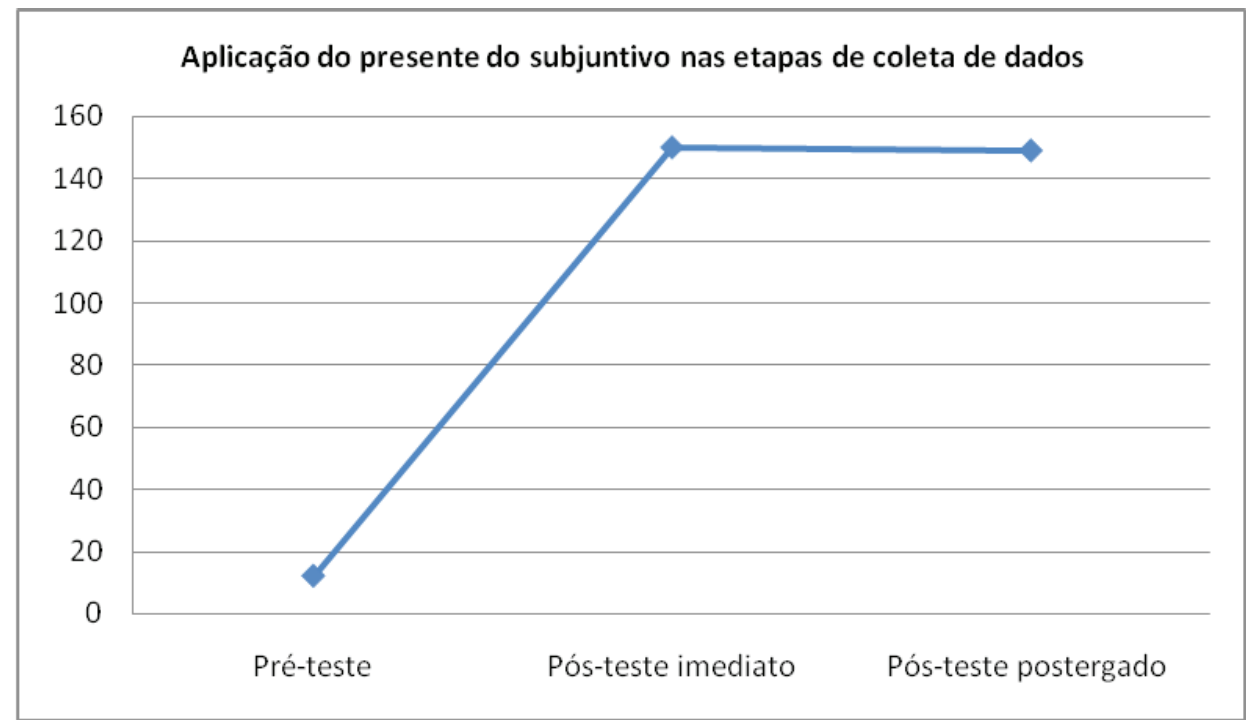

Fonte: Autores (2018)

A partir do Gráfico 2, é possível observarmos um aumento da aplicação do presente do subjuntivo após a intervenção pedagógica, que se manteve praticamente estável na última etapa de obtenção de dados. Logo, imediatamente após a exposição dos participantes ao conjunto de estratégias pedagógicas constitutivas da intervenção, ocorreu o aumento da forma-alvo em orações temporais em espanhol. Esses resultados sugerem efeitos instrucionais duráveis, os quais estão em consonância com outros trabalhos (LIMA JÚNIOR, 2008; PASQUALI, 2012; MORAES, 2014; DUTRA, 2015), nos quais houve a permanência dos efeitos instrucionais.

A intervenção pedagógica deste estudo basicamente envolveu, além de tarefas de produção, instrução explícita e contraste de uso de orações temporais com ideia de futuro no PB e no espanhol. É possível observarmos que o uso de um conjunto de estratégias pedagógicas destinadas ao direcionamento da atenção dos aprendizes para o emprego do presente do subjuntivo em orações temporais, em espanhol, surtiu efeitos positivos em termos de diminuição da influência de conhecimento linguístico prévio e aumento da forma-alvo. Na literatura da ASL (DUTRA, 2015), o planejamento e a execução de intervenção dessa natureza destinada ao ensino de aspectos linguísticos problemáticos apresentaram evidências favoráveis ao processo de aprendizagem dos clíticos acusativos e dativos de terceiras pessoas do espanhol por universitários brasileiros, conforme já foi mencionado. 
Além disso, estudos de síntese narrativa (SPADA, 1997) e de meta-análise (NORRIS; ORTEGA, 2000; SPADA; TOMITA, 2010) têm apontado resultados benéficos da instrução explícita na ASL. No contexto brasileiro, houve pesquisas sobre a IFF que corroboraram os efeitos positivos desse tipo de intervenção pedagógica em relação à aquisição de aspectos linguísticos; além do aumento da forma-alvo, ocorreu também a redução de transferência linguística (LOOSE, 2006; DUTRA, 2015).

Somado a isso, é válido ressaltarmos que a produção linguística pode permitir a percepção da lacuna existente entre a língua do aprendiz e a língua-alvo (SWAIN, LAPKIN, 1995). Nesse sentido, conjecturamos que a execução por parte dos participantes deste estudo de tarefas de produção (escrita/oral) tenha possibilitado a percepção de que o uso de formas alternativas, em orações temporais, em espanhol, não condizia com o esperado: a presença do presente do subjuntivo.

Por último, a administração de estudo contrastivo no que tange ao uso do futuro do subjuntivo e do presente do subjuntivo, respectivamente, entre o PB e o espanhol, de maneira integrada às outras estratégias pedagógicas, parece ter surtido efeito benéfico na aprendizagem da forma-alvo. Boéssio (2003) ressalta a importância do contraste entre as línguas próximas no ensino de L2/LE. Nessa linha, concordamos com a afirmação a respeito da eficiência e da necessidade da indicação aos aprendizes do limite de proximidade interlinguística, enfatizando os aspectos divergentes (DUTRA, 2015).

\section{CONSIDERAÇÕES FINAIS}

Esta investigação nos possibilitou examinar a interação entre o tratamento instrucional e a produtividade das formas alternativas utilizadas no lugar do presente do subjuntivo, em tarefas de produção entre universitários brasileiros de um curso de Letras. Para nortearmos esta pesquisa, partimos de objetivos e de hipóteses, os quais retomamos, na sequência, a fim de tecermos as considerações finais do presente estudo.

O nosso primeiro objetivo estava relacionado aos efeitos e à durabilidade do tratamento instrucional sobre a frequência das formas alternativas. Em relação a essa questão, nossa Hipótese (i), a respeito dos efeitos e da durabilidade da IFF sobre a produtividade das formas não alvo, foi confirmada. De modo geral, as estruturas alternativas reduziram sua aplicação no pós-teste imediato, em curto prazo. Este efeito se manteve praticamente estável no pós-teste postergado, em médio prazo. 
O segundo objetivo estava atrelado à existência de casos de transferência linguística na aprendizagem de aspecto linguístico em situação de línguas próximas. Nossa Hipótese (ii) sobre essa questão também foi confirmada. É necessário ressaltarmos que foi recorrente o emprego do futuro do subjuntivo no uso de orações temporais com ideia de futuro no espanhol, ou seja, houve o apoio prioritário na LM (VILLALBA, 2004).

Os resultados obtidos sugerem, do ponto de vista didático-pedagógico, que o uso de múltiplas estratégias pedagógicas no ensino de línguas próximas surte efeito benéfico. Entretanto, concordamos com Dutra (2015) e ressaltamos a relevância de estudo contrastivo tendo em vista aspectos divergentes, em situação de línguas tipologicamente próximas. Logo, é de extrema relevância que se assinalem os limites de proximidade interlinguística.

Quanto às contribuições teórico-metodológicas, se partirmos do pressuposto de que existe uma relação inversamente proporcional entre a forma-alvo e as formas não alvo nas fases pós-tratamento instrucional, assinalamos a utilização de dados de não aplicação da forma-alvo como recurso para a indicação dos efeitos benéficos da intervenção pedagógica. Acrescentamos a isso, entre as formas alternativas, a existência de transferência da regra do PB na aprendizagem do presente do subjuntivo em orações temporais. Nesse sentido, estamos de acordo com Villalba (2002), para a qual a transferência linguística pode ser uma estratégia de comunicação.

Além disso, a partir dos resultados do presente estudo e das investigações dentro da área de aquisição do espanhol por brasileiros (CRUZ, 2001; VILLALBA, 2002, 2004; BOÉSSIO, 2003; LOOSE, 2006; DUTRA, 2015), podemos tecer as seguintes considerações: (i) a proximidade interlinguística facilita a transferência de estruturas linguísticas propriamente ditas, ou o uso de regras do PB no processo de aprendizagem do espanhol; (ii) línguas tipologicamente próximas parecem motivar a influência da LM no processo de aprendizagem da língua-alvo em razão da ausência da percepção dos limites de proximidade e de distância das áreas das gramáticas das línguas envolvidas; (iii) estratégias pedagógicas destinadas à delimitação da proximidade interlinguística e, primordialmente, dos pontos divergentes entre a LM e a LE/L2 podem ser úteis no processo de aprendizagem de línguas próximas.

\section{REFERÊNCIAS BIBLIOGRÁFICAS:}

BITTENCOURT, D.L.R. de. (2012). O uso do futuro do subjuntivo: variação e frequência. Interdisciplinar, v. 16, pp. 117-130. 
A aprendizagem do presente do subjuntivo do espanhol em orações temporais ...

BOÉSSIO, C.P.D. (2003). A transferência indevida do infinitivo flexionado no ensino do espanbol para brasileiros. Dissertação de Mestrado em Letras. Escola de Educação, UCPel, Pelotas.

BOSQUE, I.; DEMONTE, V. (1999). Gramática descriptiva de la lengua española: las construcciones sintácticas fundamentales. Madrid: Espasa Calpe.

CAMARA JR., J.M. (1970). Estrutura da língua portuguesa. Petrópolis: Vozes.

CAMARA JR., J.M. (1979). História e estrutura da língua portuguesa. Rio de Janeiro: Padrão.

CANALE, M. (1983). From communicative competence to communicative language Pedagogy. In: RICHARDS, J.; SCHMIDT, R. (Eds.) Language and communication. London: Longman.

CASTILHO, A. T. (2010). Nova gramática do português brasileiro. São Paulo: Contexto.

CASTRO, F. (2003). Uso de La Gramatica Intermedio. Edelsa - Disal: Madrid.

COMRIE, B.; HOLMBACK, H. (1984). The future subjunctive in Portuguese: a problem in semantic theory. Lingua, n. 63, pp. 213-253.

COSTA, G.V.M. (2004). O uso do presente do subjuntivo em língua espanbola: contribuição para aprendizes brasileiros. Dissertação de Mestrado em Letras. Escola de Educação, UCPel, Pelotas.

CRUZ, M.L.O.B. (2001). Estágios de interlíngua: estudo longitudinal centrado na oralidade de sujeitos brasileiros aprendizes de espanhol. Tese de Doutorado em Linguística Aplicada. Instituto de Estudos da Linguagem, Unicamp, Campinas.

DÖRNYEI, Z.; KORMOS, J. (1998). Problem-solving mechanisms in L2 communication: A psycholinguistic perspective. Studies in Second Language Acquisition, 20, pp. 349-385.

DOUGHTY, C.; WILLIAMS, J. (1998). Focus on form: theory, research, and practice. (Ed). Focus on form in classroom second language acduisition. Cambridge: CUP.

DUTRA, E. de O. (2015). Os efeitos da Instrução com Foco na Forma na aprendizagem dos clíticos de $3^{a}$-pessoas do espanbol por universitários brasileiros. Tese de Doutorado em Linguística Aplicada. Unisinos, São Leopoldo.

ELLIS, R. (2005). La adquisición de segundas lenguas en un contexto de enseñanza. Análisis de las investigaciones existentes. Departamento Técnico del Ministerio de Educación de Nueva Zelanda. Wellington. Disponível em:<http://www.mecd.gob.es/dctm/redele/ 
Material-RedEle/Biblioteca/2006_BV_05/2006_BV_05_04Ellis.pdf?documentId= 0901e72b80e3a029>.Acesso em: 8 set. 2014.

ELLIS, R. (2011). Second Language Acquisition. Oxford. New York.

FÁBREGAS, A. (2014). A guide to subjunctive and modals in Spanish: questions and analyses. Borealis: An International Journal of Hispanic Linguistics, v. 3, n. 2, pp. 1-94.

GASS, S.; SELINKER, L. (1992). Language Transfer in Language Learning. Revised Edition. Philadelphia: John Benjamins.

GÓMEZ, R.P. (2004). Vademécum para la formación de profesores. Enseñar español como segunda lengua (L2)/ lengua extranjera (LE) Directores: Jesús Sánchez Lobato e Isabel Santos Gargallo SGEL, Sociedad General Española de Librería, Madrid.

GONZÁLEZ, N.T.M. (1994). Cadê o pronome? O gato comeu. Tese de Doutorado em Letras. USP, São Paulo.

HOWATT, A.P.R. (1984). A History of English language teaching. Oxford: Oxford University Press.

ILARI, R.; BASSO, R. (2009). O português da gente: a língua que estudamos, a língua que falamos. São Paulo: Contexto.

KANWIT, M.; GEESLIN, K.L. (2014). The interpretation of Spanish subjunctive and indicative forms in adverbial clauses: a cross-sectional study. Studies in Second Language Acquisition, n. 36, pp. 487-533.

KEHDI, V. (2007). Morfemas do português. São Paulo: Ática.

KODA, K. (1997). Orthographic knowledge in L2 lexical processing. A cross-linguistic erspective. In: COADY, J.; HUCKIN, T. Second language vocabulary acquisition. Cambridge: Cambridge University Press.

KRASHEN, S. (1982). Principles and practice in second language acquistion. New York: Pergamon Press.

LIGHTBOWN, P.M.; SPADA, N. (2013). How languages are learned. $4^{\mathrm{a}}$ ed. Oxford: Oxford University Press. 
A aprendizagem do presente do subjuntivo do espanhol em orações temporais ...

LIMA JÚNIOR, R.M. (2008). Pronunciar para comunicar: uma investigação do efeito do ensino explícito da pronúncia na sala de aula de LE. Dissertação de Mestrado em Linguística Aplicada. UnB, Brasília.

LONG, M. (1991). Focus on form: a design feature in language teaching methodology. In: DE BOT, K. et al. (Ed.). Foreign - Language Research in Cross-Cultural Perspective. Amsterdam: Benjamins, pp. 39-52.

LOOSE, R.E. (2006). O papel da Instrução Explícita na Aquisição/Aprendizagem de Estruturas do Espanbol por falantes do Português. Dissertação de Mestrado em Linguística Aplicada. Escola de Educação, UCPel, Pelotas.

MATTE BON, F. (1995). Gramática comunicativa del español: de la idea a la lengua. Tomo I. Madrid: Edelsa.

MATTOS E SILVA, R.V. (2006). O português arcaico: fonologia, morfologia e sintaxe. São Paulo: Contexto.

MOLLICA, M.C. (2003). Da linguagem coloquial à escrita padrão. Rio de Janeiro: 7Letras.

MORAES, G.B. de. (2014). A aprendizagem do presente do subjuntivo do espanbol por alunos brasileiros: um estudo com foco na forma. Tese de Doutorado em Linguística Aplicada. Unisinos, São Leopoldo.

MOURA NEVES, M.H.de. (2000). Gramática de usos do português. São Paulo: UNESP.

NORRIS, J.; ORTEGA, L. (2000). Efectiveness of L2 instruction: A research synthesis and quantitative meta-analysis. Language Learning, 50, pp. 417-528.

ODLIN, T. (1989). Language transfer: cross-linguistic influence in language learning. Cambridge: Cambridge University Press, pp. 1-18.

OTTONELLO, M.B. (2004). Vademécum para la formación de profesores. Enseñar español como segunda lengua (L2)/ lengua extranjera (LE) Directores: Jesús Sánchez Lobato e Isabel Santos GargalloSGEL, Sociedad General Española de Librería, Madrid.

PASQUALI, E. (2012). O papel da instrução explícita e da memória de trabalbo na leitura em L2. Dissertação de Mestrado em Letras. UCPel, Pelotas.

PIMPÃO, T.S. (2015). Mapeamento do uso variável do modo subjuntivo no português do Brasil. Working Papers em Linguística, v. 16, n. 1, pp. 120-141. 
SANTOS, J.F.G. (1993). Sintaxis del Español - Nivel de Perfeccionamiento. Santillana.

SCHMIDT, R. (2001). Attention. In: ROBINSON, P. (ed.) Cognition and second language instruction. Cambridge: Cambridge University Press, pp. 3-32.

SCHROEDER, D. N. (2004). Ensino de Italiano L2: a aquisição dos pronomes. 1. ed. Passo Fundo: UPF Editora.

SELINKER, L. (1992). Rediscovering interlanguage. Londres: Longman.

SPADA, N. (1997). Form-focused instruction and second language acquisition: A review of classroom and laboraty research. Language Teaching, 30, pp. 73-87.

SPADA, N. (2010). Beyond form-focused instruction: Reflections on past, present and future research. Language Teaching, 44, pp. 225-236.

SPADA, N. (2014). Instructed second language acquisition research and its relevance for L2 teacher education. Education Matters, v. 2, pp. 41-54.

SPADA, N.; TOMITA, Y. (2010). Interactions between type of instruction and type of language feature: A meta-analysis. Language Learning, 60(2), pp. 1-46.

SWAIN, M. (1995). Three functions of output in second language learning. In: COOK, G.; SEIDLHOFER, B. (Orgs.). Principles and practice in applied linguistics: Studies in honour of H. G. Widdowson. Oxford, UK: Oxford University Press, pp. 125-144.

SWAIN, M. (1998). Atención a la forma através de la reflexión consciente. In: DOUGHTY, C.; WILLIAMS, J. (orgs.). Atención a la Forma en la Adquisición de Segundas Lenguas en el aula. Traduccción y Edición Española Editorial Edinumen.

SWAIN, M. (2005). The output hypothesis: Theory and research. In: HINKEL, E. (Org.). Handbook on research in second language teaching and learning. New Jersey: Lawrence Erlbaum Associates, pp. 471-483.

SWAIN, M.; LAPKIN, S. (1995). Problems in output and cognitive processes they generate: a step toward second language learning. Applied Linguistics, v. 16, pp. 371-391.

VEIDMARK, R.R.; AGUIAR, J.U. (1991). La desaparición del subjuntivo español y sus implicaciones para el cambio linguístico. Filología e Linguística, v. XVII, n. 1-2, pp. 193-202. 
A aprendizagem do presente do subjuntivo do espanhol em orações temporais ...

VESTERINEN, R.; BYLUND, E. (2013). Towards a unified account of the Spanish subjunctive mood: epistemic dominion and dominion of effective control. Lingua, $\mathrm{n}$. 131, pp. 179-198.

VILLALBA, T.K.B. (2002). Pepe vio que no tiene jeito, su mujer es asi mismo: as delicadas relações lexicais entre a L1 e a L2 na aquisição de espanhol por universitários brasileiros. Tese de Doutorado em Letras, UFRGS, Porto Alegre.

VILLALBA, T.K.B. (2004). O mito da língua fácil na aprendizagem de Espanhol por falantes brasileiros. Calidoscópio (UNISINOS), Unisinos, v. 2, n.1, pp. 101-107.

Recebido: 07/08/2017

Aceito: 04/01/2018 